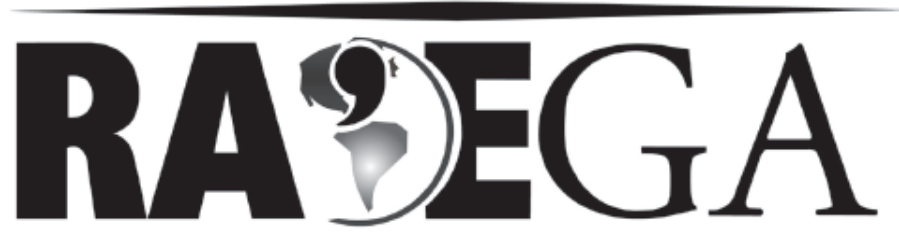

O ESPAÇO GEOGRÁFICO EM ANÁLISE

\title{
OS MICROCLIMAS DA UNIVERSIDADE FEDERAL DE MATO GROSSO/CUIABÁ
}

\section{The microclimate of the Cuiabá campus of Mato Grosso Federal University}

\author{
Elis Dener Lima ALVES ${ }^{1}$ \\ Marcelo Sacardi BIUDES ${ }^{2}$
}

\section{RESUMO}

A presente pesquisa teve como objetivo principal caracterizar espacialmente a temperatura e a umidade relativa do ar na Universidade Federal de Mato Grosso, campus de Cuiabá em dois períodos: abril (final do período chuvoso) e setembro (período seco), em três horários, às $8 \mathrm{~h}, 14 \mathrm{~h}$ e $20 \mathrm{~h}$. Para tanto, utilizou-se da técnica de transectos móveis para a coleta de dados de temperatura do ar, umidade relativa e coordenadas geográficas. A caracterização microclimática permitiu verificar que a região do zoológico e de bosque (sudoeste do campus) apresentou os maiores valores de umidade relativa do ar, aproximadamente $55 \%$, enquanto que a região mais pavimentada, próxima a um estacionamento, apresentou umidade relativa baixa (42\%). No período seco, a maior amplitude da temperatura do ar $\left(3,6^{\circ} \mathrm{C}\right)$ ocorreu às $14 \mathrm{~h}$, no dia 12/09/2010, neste dia boa parte do campus apresentou temperatura de $42,7^{\circ} \mathrm{C}$ e umidade relativa na faixa de $16,1 \%$. A maior amplitude da umidade foi verificada às $8 \mathrm{~h}$ e às $20 \mathrm{~h}$, nos dias 13 e 16, respectivamente. As áreas que apresentaram maior temperatura foram próximas ao Restaurante Universitário (RU) e ao campo de futebol, com média de $38,9^{\circ} \mathrm{C}$, devido à falta de arborização local.

Palavras-chave: microclima; temperatura do ar; umidade relativa do ar.

\footnotetext{
${ }^{1}$ Mestre em Física Ambiental, Universidade Federal de Mato Grosso, elisdener@hotmail.com

2 Doutor em Agricultura Tropical, Professor do Instituto de Física da Universidade Federal de Mato Grosso, marcelo@pgfa.ufmt.br
} 


\section{ABSTRACT}

This study aimed to characterize spatially the main temperature and relative humidity at the Federal University of Mato Grosso, Cuiabá campus in two periods: April (end of rainy season) and September (dry season), three times at $8 \mathrm{am}, 14 \mathrm{~h}$ and $20 \mathrm{~h}$. To this end, we used the technique of mobile transects to collect data of air temperature, relative humidity and geographic coordinates. The microclimatic showed that the region of the zoo and Grove (southwest of campus) showed the highest values of relative humidity, approximately $55 \%$, while the area paved over, next to a parking lot, showed low relative humidity (42\%). During dry season, the highest amplitude of air temperature (3.6 C) occurred at $14 \mathrm{~h}$, on $12 / 09 / 2010$, this day much of the campus showed a

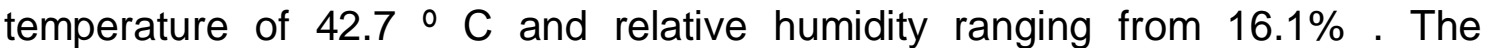
broadening of moisture was observed at $8 \mathrm{~h}$ and $20 \mathrm{~h}$ on days 13 and 16 , respectively. The areas with higher temperature were close to the University Restaurant (UK) and the football field, averaging $38.9^{\circ} \mathrm{C}$, due to lack of local trees.

Keywords: microclimate; air temperature; relative humidity.

\section{INTRODUÇÃO}

As variações no clima ocorrem de forma natural, devido a vários fatores, como: precessão dos equinócios, oscilação da órbita terrestre, etc. No entanto, a partir da segunda metade do século XX com as intensas modificações introduzidas no meio natural, ocasionadas pelo processo de urbanização, o clima passou a ter outro agente modificador, o homem.

A partir de então, cientistas, governantes, e a sociedade em geral, iniciaram as discussões sobre as transformações que poderiam ocorrer no comportamento climático. Essas mudanças podem estar relacionadas com 0 aumento da concentração de CO2 na atmosfera, oriundas do maior consumo pela sociedade moderna (Davis et al, 2010).

Acredita-se que o aumento do $\mathrm{CO}_{2}$, faz com que a temperatura se eleve, intensificando o efeito estufa, e em conseqüência, modifica o comportamento de vários elementos meteorológicos, provocando chuvas intensas em alguns 
locais, e secas prolongadas em outros (kreuzwieser \& Gessler, 2010; Vörösmarty et al, 2000) .

Todavia, essas discussões se limitam, muita das vezes, às mudanças climáticas na escala global. Entretanto, as mudanças no ritmo climático são mais sensivelmente observadas em escalas menores.

$\mathrm{Na}$ escala regional as condições ambientais são determinadas por um conjunto de fatores de superfície, entre eles, a distribuição entre as áreas continentais e oceânicas, forma dos continentes, correntes marítimas e rugosidade dos continentes. Todos os elementos que influenciam na escala global e regional, interferem na escala local (Ribeiro, 1993).

O exemplo mais significativo da escala local são as cidades. Nessa escala o homem pode contribuir mais significativamente com os fatores de modificação das condições ambientais, através de alterações na cobertura do solo, como substituição da vegetação pela construção desordenada.

No clima local está inserido o microclima, onde as feições ou estruturas particularizadas (prédios, pavimentos, inclusive objetos, plantas e pessoas) são os principais responsáveis pela sua variabilidade. A microrrugosidade, a cor e a textura das superfícies, aliadas aos abrigos dispostos junto ao solo interagem, criando um mosaico de facetas, no qual qualquer modificação pode interferir no comportamento microclimático (Ribeiro, 1993).

O estudo de Shashua-Bar et al (2010) constataram a importância das árvores no meio urbano para atenuar o efeito de ilha de calor em um verão quente e úmido. No qual o efeito térmico da árvore foi dependente principalmente de seu nível de cobertura do dossel e densidade de plantio nas ruas de Tel Aviv em Israel.

Streiling \& Matzarakis (2003) analisaram efeitos das árvores isoladas e pequenos aglomerados de árvores no bioclima de Fahnenbergplatz, no centro da cidade de Freiburg no sudoeste da Alemanha e constataram o efeito positivo das árvores no ambiente térmico. Em particular, a radiação média da temperatura, e o índice térmico mostraram-se distintos entre as áreas com árvores e áreas sem árvores, apesar do pequeno tamanho da área de investigação. 
Existem estudos que demonstram que um parque com superfícies gramadas e arborizadas, pode ser mais quente que os seus arredores. Jauregui (1990-1991) explicou que as elevadas temperaturas do parque Chapultepec na Cidade do México durante a manhã ocorreu pelo rápido aquecimento do mesmo, devido a sua menor inércia térmica em comparação com a área urbana. Enquanto, Potchter et al (2003) relataram que um parque coberto de grama, não é apenas mais quente que um parque coberto de árvores, mas também era mais quente que seu entorno construído durante o dia.

A relevância de estudos de natureza microclimática está em viabilizar maior conhecimento sobre o microclima, essencialmente no que se refere às mudanças climáticas locais associadas ao uso e ocupação do solo. Por isso se faz importante um estudo desse gênero na Universidade Federal de Mato Grosso (UFMT), campus de Cuiabá, pois sua construção não teve um planejamento adequado, em que se privilegiou apenas o construir, sem estudo prévio de como essas construções alterariam o microclima do campus. Mesmo porque, esses tipos de estudo e suas aplicações são recentes (Potchter et al, 2003; Streiling \& Matzarakis, 2003; Jansson, 2006; Wong et al, 2007; ShashuaBar et al, 2010).

Nesse sentido, o objetivo desse trabalho foi caracterizar espacialmente a temperatura e a umidade relativa do ar no campus de Cuiabá da UFMT. Afim de propor sugestões ao planejamento do campus em concordância com o ambiente térmico e higrométrico do mesmo.

O principal agente modificador do clima em escala microclimática são os materiais de construção, pois estes desempenham um papel fundamental no comportamento da temperatura e da umidade relativa do ar. As suas características óticas e térmicas são reguladas por dois principais fatores, 0 albedo e a emissividade. Materiais com baixo albedo e emitância, aumentam a transferência de energia para o ar ambiente, aquecendo-o (Prado \& Ferreira, 2005).

Variações nas características da superfície alteraram o clima local, mediante modificação do equilíbrio de energia entre a superfície e a camada 
limite, levando a distintos microclimas (Offerle et al, 2005). Essas variações provocam anomalias na temperatura e na umidade relativa do ar, tendo seu efeito mais significativo representado pelas ilhas de calor, que estão relacionadas ao aumento da temperatura do ar da periferia para o centro das cidades, por sua configuração espacial (Kolokotroni et al, 2007; Gartland, 2010).

Um fator minimizador das ilhas de calor são as áreas vegetadas, pois atuam no controle da incidência solar, da temperatura, umidade do ar, dos ventos, das chuvas.

\section{MATERIAIS E MÉTODOS}

\section{ÁREA DE ESTUDO}

A área de estudo, Universidade Federal de Mato Grosso (UFMT), constitui-se em construções dispostas sem qualquer estudo relacionado com a climatologia urbana. Atribui-se a isso a falta de profissionais capacitados para realizar um estudo aprofundado das condições existentes no campus e do futuro impacto ambiental que as edificações ocasionariam. Em 1969 o campus da UFMT contava com apenas 2.890,00 $\mathrm{m}^{2}$ de área construída, em 1977 passou para 25.396,00 m². Atualmente o campus de Cuiabá abriga uma área construída de 83.111,60 $\mathrm{m}^{2}$ incluindo pista/campo de futebol e parque aquático, distribuída em 74 ha do campus (Campos Neto, 2007).

O campus de Cuiabá da UFMT apresenta um ambiente heterogêneo, com diferentes padrões de uso e ocupação do solo, dentre os quais se pode destacar os locais de áreas verdes (bosques) que são utilizados pelos estudantes e visitantes, para esporte e lazer. O zoológico contém uma lagoa e vegetação. Campo de futebol possui elevada área aberta com vegetação rasteira (gramado) circundado por uma pista de corrida. Áreas expostas (solo 
nu) sem presença de vegetação. Áreas impermeabilizadas, estacionamentos, vias pavimentadas, faculdades e institutos (Figura 1).

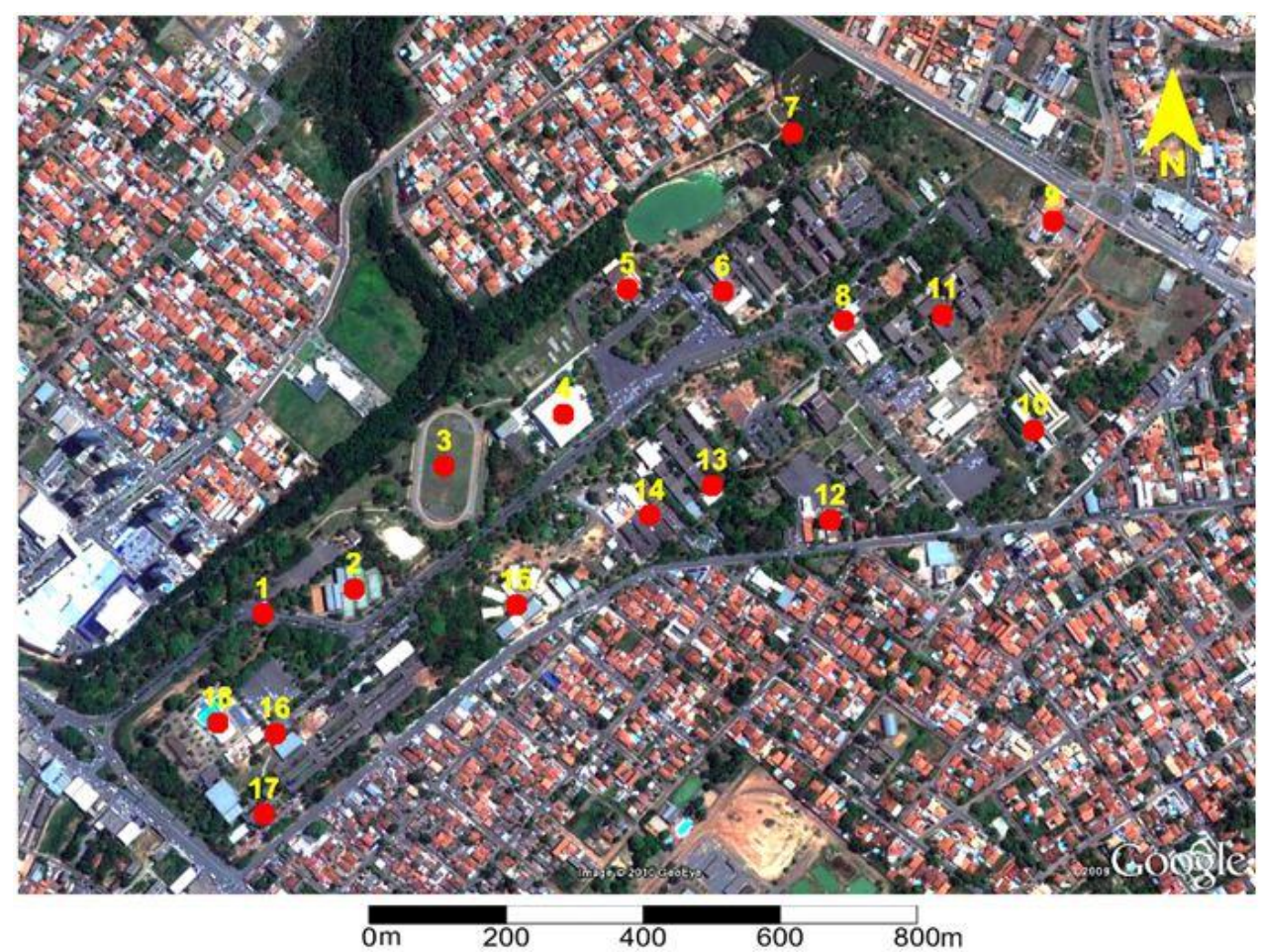

1 - Portaria/Guarita ABC; 2 - Quadras Múltiplas; 3 - Campo de Futebol; 4 - FEF (Faculdade de Educação Física / Ginásio de Esportes); 5 - Restaurante Universitário; 6 - ICET (Instituto de Ciências Exatas e da Terra); 7 - Zoológico; 8 - PPGFA (Programa de Pós-Graduação em Física Ambiental); 9 - Prefeitura do Campus; 10 - Bloco "Casarão"; 11 - IB (Instituto de Biociência); 12 - SINTUF (Sindicato dos Trabalhadores da UFMT); 13 - FENF (Faculdade de Engenharia Florestal); 14 - FAMEV (Faculdade de Agronomia e Medicina Veterinária); 15 - Centro Cultural; 16 - ICHS (Instituto de Ciências Humanas e Sociais); 17 - IE (Instituto de Educação); 18 - Parque Aquático.

FIGURA 1 - LOCALIZAÇÃO DE INSTITUTOS, FACULDADE E PRINCIPAIS LOCAIS DO CAMPUS DE CUIABÁ DA UFMT.

\section{ROTEIRO METODOLÓGICO}

Para a caracterização espacial da temperatura e umidade relativa do ar foram realizados transectos móveis (Figura 2) que buscaram contemplar os diferentes padrões de ocupação do solo, observados por meio da combinação de dados cartográficos, e visitas em campo. O tempo médio de percurso foi 25 
minutos, minimizando os efeitos das diferentes intensidades da radiação produzidos pela variação da altura aparente do sol. Os transectos foram realizados no período de 19 a 29 de abril de 2010, final do período chuvoso, e 08 a 17 de setembro, período seco. Os horários estabelecidos foram às $8 \mathrm{~h}$, às $14 \mathrm{~h}$ e às $20 \mathrm{~h}$.

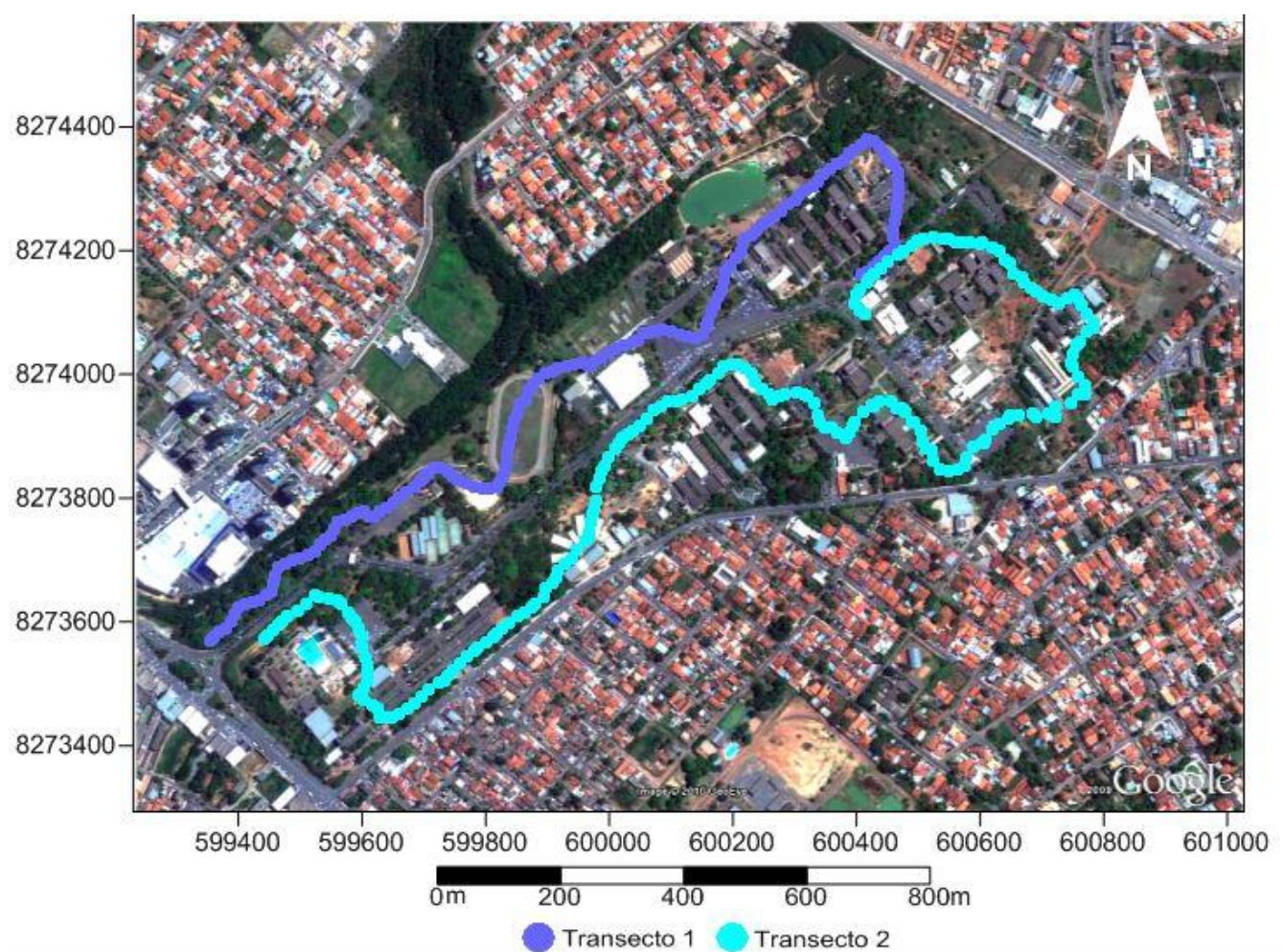

FIGURA 2 - TRANSECTOS MÓVEIS REALIZADOS NO CAMPUS DE CUIABÁ-UFMT.

$\mathrm{Na}$ realização dos transectos foram utilizados dois Termo-higrômetros (modelo HT-4000, fabricante ICEL Manaus) e dois GPS (Global Positioning System, modelo 76CSx, fabricante Garmin), nos quais foram ajustados para registrar e armazenar os dados das variáveis (temperatura, umidade, e coordenadas) a cada 10 segundos. Em função da velocidade média ao longo do transecto, registrada pelo receptor do GPS $(1,4 \mathrm{~m} / \mathrm{s})$ cada ponto do transecto encontra-se a uma distância média de $14 \mathrm{~m}$ dos outros pontos adjacentes. O percurso dos transectos 1 e 2, foi de aproximadamente 1,9 km e 
2,6 km, registrando em média 132 e 183 pontos, respectivamente, totalizando em média, 315 dados de temperatura e umidade relativa do ar georreferenciados.

Para a realização das coletas, os termo-higrômetros foram instalados abaixo de uma cobertura de isopor para protegê-los da radiação solar direta, mantendo a aproximadamente um metro do operador e a 1,5 $\mathrm{m}$ do solo. Antes do início de cada coleta, os sensores foram mantidos sobre o gramado do ponto inicial por aproximadamente 15 minutos, para se aclimatarem com 0 ambiente externo.

\section{TRATAMENTO DOS DADOS}

Após a realização da coleta dos dados foi estruturado um banco de dados, em função do horário da medição, com as variáveis; temperatura, umidade do ar e coordenadas geográficas. Utilizou-se do test-t para se verificar se as coletas de dados em abril apresentaram diferenças significativas em relação às coletas realizadas em setembro.

Foram confeccionados semivariogramas, cujos ajustes resultaram em um modelo que melhor representou a variabilidade dos dados. Os parâmetros de ajuste como efeito pepita, patamar e alcance foram utilizados para a construção dos mapas térmicos e higrométricos de superfícies contínuas, confeccionados por krigagem ordinária, sobrepostos aos mapas do levantamento cartográfico. As krigagens foram elaboradas no software Gamma Design 7.0 e os mapas de temperatura e umidade pelo software Surfer® 9.8. Utilizou-se para discussão os mapas que apresentaram melhor ajuste do semivariograma para cada horário de coleta.

\section{RESULTADOS E DISCUSSÕES}

\section{ANÁLISE EXPLORATÓRIA DOS DADOS}

Em média, para cada horário de coleta, foram realizadas 2360 observações. Na tabela 1 observa-se que às $8 \mathrm{~h}$, e às $14 \mathrm{~h}$ os menores valores 
de temperatura ocorreram na coleta de abril, no entanto, às $20 \mathrm{~h}$ o valor mínimo foi verificado em setembro $\left(22,9^{\circ} \mathrm{C}\right)$, em função da entrada de uma massa de ar fria neste período. Em relação à média, setembro apresentou em todos os horários os maiores valores, observa-se também que o valor máximo foi verificado em setembro, no horário das $14 \mathrm{~h}\left(42,7^{\circ} \mathrm{C}\right)$ este fato se deve, principalmente, a dois fatores, a falta de chuvas e a poluição atmosférica ocasionada pelas queimadas. $\mathrm{O}$ maior desvio padrão $\left( \pm 3,2^{\circ} \mathrm{C}\right)$ da temperatura do ar ocorreu às $14 \mathrm{~h}$ em setembro, e o menor $\left( \pm 1,6^{\circ} \mathrm{C}\right)$ às $20 \mathrm{~h}$ em abril, revelando que a maior variabilidade térmica ocorreu em setembro.

Em relação à umidade relativa do ar a diferença entre os dois períodos de coleta fica mais evidente, nota-se uma elevada diferença em todos os horários, tanto para o valor mínimo, médio e máximo. Observa-se que em setembro, ás $14 \mathrm{~h}$, a umidade relativa do ar atingiu os $16,7 \%$, valor considerado prejudicial à saúde segundo a OMS (Organização Mundial de Saúde). Nota-se que a média higrométrica para setembro esteve baixa em todos os horários, sendo que a menor média ocorreu às $14 \mathrm{~h}(25,2 \%)$ e a maior às $8 \mathrm{~h}(42,5 \%)$. Enquanto que em abril a umidade esteve relativamente elevada, com valores que variaram em média de $51,8 \%$ às $14 \mathrm{~h}$ a $75,2 \%$ às $20 \mathrm{~h}$.

Quanto ao desvio padrão, os valores da umidade relativa do ar estiveram superiores aos da temperatura, apresentando um desvio de $\pm 14,3 \%$ às $20 \mathrm{~h}$ na coleta de setembro, deste modo nota-se que a variabilidade dos dados em setembro esteve superior a variabilidade do mês de abril, tanto para a temperatura do ar como para a umidade relativa, conforme a tabela 1.

Foi aplicado um test-t com a hipótese de que as variâncias eram equivalentes, com um nível de significância $\alpha=0,005$, sendo que a hipótese testada seria válida se $p$-value $>0,005$, como este esteve, para todos os horários, abaixo do nível de significância a hipótese testada não deve ser aceita, pois a diferença de médias é significativa. Portanto, pode-se dizer que as coletas de abril e setembro tanto da temperatura como da umidade relativa do ar, em todos os horários, apresentaram valores discrepantes. Essa constatação reforça a ideia da coleta de dados em abril e setembro, pois nestes meses as condições termo-higrométricas são diferentes. 
TABELA 1 - ESTATÍSTICA DESCRITIVA E TESTE-T PARA DUAS AMOSTRAS PRESUMINDO VARIÂNCIAS EQUIVALENTES PARA A TEMPERATURA E UMIDADE RELATIVA DO AR NAS DUAS COLETAS DE DADOS (ABRIL E SETEMBRO DE 2010).

\begin{tabular}{|c|c|c|c|c|c|c|c|c|c|c|}
\hline Variável & hs & mês & $\mathrm{n}$ & Mín. & Méd. & Máx. & Des. pad. & $\alpha$ & $\mathrm{p}$-value & $\mathrm{t}$ \\
\hline \multirow{6}{*}{ Temp. } & \multirow{2}{*}{$8 \mathrm{~h}$} & abr & 2208 & 24,5 & 29 & 32,9 & 2,2 & \multirow{2}{*}{0,05} & \multirow{2}{*}{0} & \multirow{2}{*}{$-26,2$} \\
\hline & & set & 2504 & 26,3 & 30,7 & 35 & 2,2 & & & \\
\hline & \multirow{2}{*}{$14 \mathrm{~h}$} & abr & 2239 & 28,2 & 34,8 & 38,2 & 2,8 & \multirow{2}{*}{0,05} & \multirow{2}{*}{0} & \multirow{2}{*}{$-47,5$} \\
\hline & & set & 2642 & 30,5 & 38,9 & 42,7 & 3,2 & & & \\
\hline & \multirow{2}{*}{$20 \mathrm{~h}$} & $a b r$ & 2279 & 25,3 & 28,3 & 32,1 & 1,6 & \multirow{2}{*}{0,05} & \multirow{2}{*}{0} & \multirow{2}{*}{$-24,9$} \\
\hline & & set & 2282 & 22,9 & 29,9 & 32,7 & 2,8 & & & \\
\hline \multirow{6}{*}{ Umid. } & \multirow{2}{*}{$8 \mathrm{~h}$} & $a b r$ & 2208 & 61,4 & 71,5 & 84,5 & 6,5 & \multirow{2}{*}{0,05} & \multirow{2}{*}{0} & \multirow{2}{*}{117,4} \\
\hline & & set & 2504 & 29,4 & 42,5 & 66,2 & 9,9 & & & \\
\hline & \multirow{2}{*}{$14 \mathrm{~h}$} & abr & 2239 & 35,8 & 51,8 & 74 & 9,9 & \multirow{2}{*}{0,05} & \multirow{2}{*}{0} & \multirow{2}{*}{86} \\
\hline & & set & 2642 & 16,1 & 25,2 & 55,2 & 11,4 & & & \\
\hline & \multirow{2}{*}{$20 \mathrm{~h}$} & abr & 2279 & 58,7 & 75,2 & 89 & 7 & \multirow{2}{*}{0,05} & \multirow{2}{*}{0} & \multirow{2}{*}{102,8} \\
\hline & & set & 2282 & 27,7 & 40,9 & 77,1 & 14,3 & & & \\
\hline
\end{tabular}

\section{ANÁLISE ESPACIAL DA TEMPERATURA DO AR}

A temperatura do ar variou em $2^{\circ} \mathrm{C}$ às $8 \mathrm{~h}$ do dia 25 de abril (Figura $3 \mathrm{~A}$ ), tendo essa diferença ocorrido entre áreas abertas (menor temperatura, 27,7 ) e regiões com vegetação arbórea e edifícios (maior temperatura, 29,7 ), isso se deve ao elevado calor específico da vegetação arbórea, pois possui boa quantidade água em sua estrutura, levando mais tempo para absorver e perder energia. Dessa forma, durante o dia, as áreas vegetadas aquecem lentamente, e durante o período noturno e da manhã ainda estão perdendo a energia absorvida no dia anterior, e essa energia liberada acaba aquecendo o ar, tornando assim um ambiente com temperaturas superiores no período matutino. A região próxima ao campo de futebol apresenta um cânion com vertente voltada para oeste, isto significa que neste local, no período da manhã, recebe menos energia demorando mais para se aquecer.

No mapa térmico da figura 3B do dia 11 de setembro é possível notar três grandes regiões homogêneas, a primeira região vai desde a prefeitura do campus até o ginásio de esportes, apresentando temperaturas entre $30,6^{\circ} \mathrm{C}$ a $31,2^{\circ} \mathrm{C}$, a segunda região compreende desde o SINTUF passando pelo Centro 
Cultural até o bosque do sudoeste do campus, com temperaturas intermediárias variando de $31,8^{\circ} \mathrm{C}$ a $32,2^{\circ} \mathrm{C}$, na terceira e menor região estão inclusos o Museu Rondon, o Instituto de Educação (IE), o parque aquático e o ICHS (Instituto de ciências Humanas e Sociais) com as maiores temperaturas de $32,6^{\circ} \mathrm{C}$ a $33,2^{\circ} \mathrm{C}$. Possivelmente isso se deve à construção civil e a proximidade com a Avenida Fernando Corrêa, sendo que a amplitude foi de $2,6^{\circ} \mathrm{C}$. Neste horário o céu estava parcialmente coberto, impedindo que parte da radiação direta chegasse à superfície.

O campo de futebol apresentou menores temperaturas às $8 \mathrm{~h}$ nos dois períodos de coleta (Figura 3). A região sudoeste do campus e a FAMEV apresentaram no segundo período temperaturas intermediárias, enquanto no primeiro período nestes locais verificaram-se as maiores temperaturas.

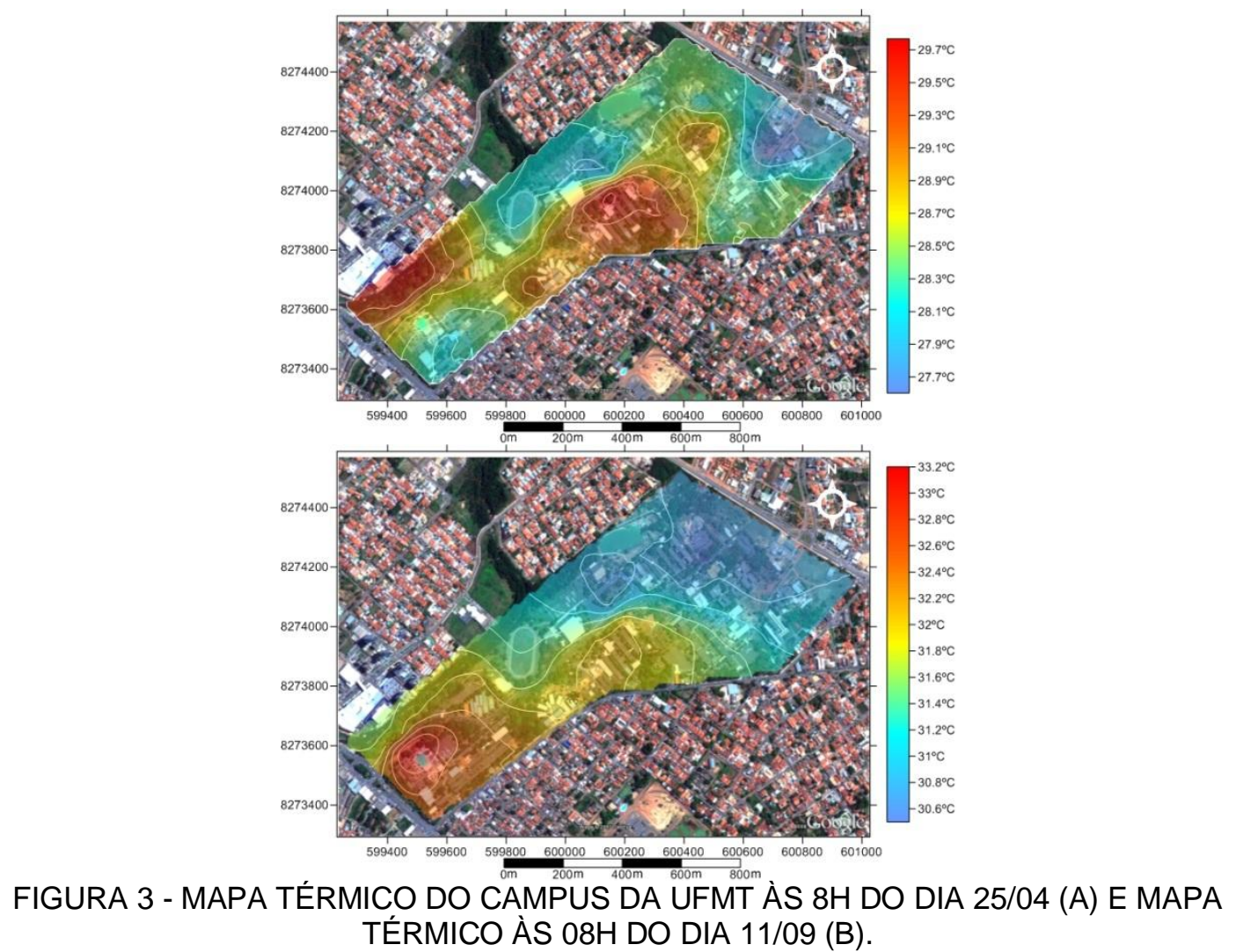


No período das $14 \mathrm{~h}$ do dia 21/04 (Figura 4A) a amplitude térmica foi de $3,3^{\circ} \mathrm{C}$, e as variáveis apresentaram padrão inverso do ocorrido às $8 \mathrm{~h}$. A região do ginásio de esportes, do RU (Restaurante Universitário) e do campo de futebol, apresentou a maior temperatura $\left(38,9^{\circ} \mathrm{C}\right)$, pela posição aparente do sol, propiciando insolação direta, e por ser uma área aberta, sem obstrução, a radiação absorvida é rapidamente reemitida em forma de ondas longas, aquecendo gradativamente 0 ar. Esse comportamento também foi observado por Potchter et al (2006) em Tel Aviv, Israel, que evidenciou que um parque urbano coberto com grama pode ser mais quente do que a área construída durante o dia.

$\mathrm{Na}$ área próxima ao IL (Instituto de Linguagem) e próxima ao PPGFA com presença de vegetação arbórea com copas fechadas, e a prefeitura do campus foram verificadas as menores temperaturas $\left(35,6^{\circ} \mathrm{C}\right)$. A presença da vegetação nesses locais foi um importante fator minimizador da temperatura do ar por interceptar a radiação solar direta, produzindo sombra.

No entanto na região sudoeste do campus, área de bosque com vegetação arbórea apresentou temperaturas intermediárias, em torno de $37,4^{\circ} \mathrm{C}$. Acredita-se que pode ter ocorrido devido à proximidade da Avenida Fernando Corrêa (pavimento asfáltico), que possui um intenso fluxo de veículos, aumentando assim a temperatura do ar na região.

Foi possível verificar na figura $4 \mathrm{~B}$ do dia 12/09 que em boa parte do campus a temperatura chegou a $42,6^{\circ} \mathrm{C}$. A área próxima ao PPGFA apresentou o menor valor $\left(39^{\circ} \mathrm{C}\right)$ o que já é elevado em termos de conforto térmico. Notase que a região de bosque apresentou as maiores temperaturas. Vale salientar que neste período de coleta a maioria das árvores perderam suas folhas diminuindo significativamente a interceptação da radiação solar. Salienta-se ainda que, provavelmente, outros fatores tenham influenciado na temperatura deste local. Podendo ter ocorrido um processo de advecção oriundo de ventos de $3,8 \mathrm{~m} / \mathrm{s}$ de direção norte transportando ar quente da área urbanizada para a região do campus, fato parecido já observado por Jansson (2006) em parques de Estocolmo na Suécia e Eliasson \& Upmanis (2000) em parques de Kùbenhavn na Dinamarca e Göteborg na Suécia. 


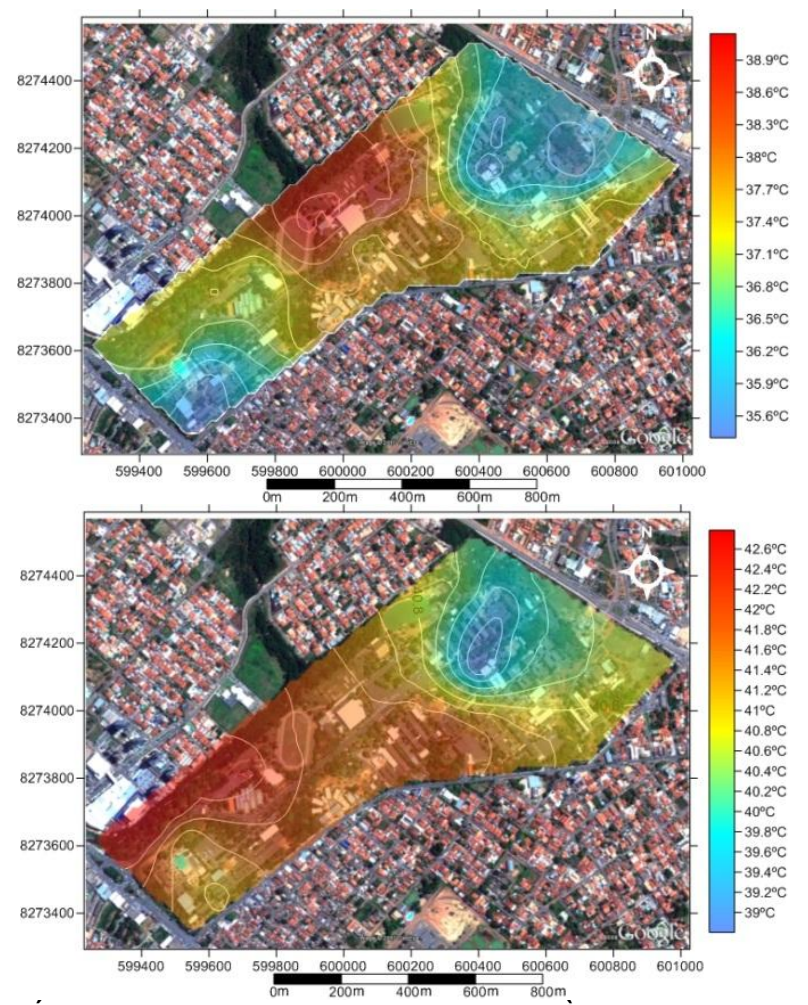

FIGURA 4 - MAPA TÉRMICO DO CAMPUS DA UFMT ÀS 14H DO DIA 21/04 (A) E MAPA TÉRMICO DO CAMPUS DA UFMT ÀS 14H DO DIA 12/09 (B).

$\mathrm{Na}$ figura $5 \mathrm{~A}$ verifica-se um mosaico de microclimas, com amplitude de $2^{\circ} \mathrm{C}$. Nota-se que as áreas vegetadas (sudoeste do campus e proximidades do centro cultural) apresentaram temperatura no valor de $28,9^{\circ} \mathrm{C}$, assim como nas proximidades da prefeitura do campus, e na área correspondente a lagoa do zoológico, locais com elevada umidade do ar, que retêm a energia absorvida, liberando-a lentamente noite adentro. Observa-se uma anomalia térmica positiva englobando a central analítica que possui um estacionamento com pavimentação asfáltica, chegando aos $30,9^{\circ} \mathrm{C}$.

No dia 16 de setembro (Figura 5B) o mapa térmico apresentou três estratificações paralelas, uma com temperaturas entre $29,4^{\circ} \mathrm{C}$ a $30^{\circ} \mathrm{C}$ que se estendeu desde o zoológico até a Guarita, a segunda estratificação ocorreu desde $O$ canil até 0 sudoeste do campus, com temperaturas de $30,4^{\circ} \mathrm{C}$ a $31,2^{\circ} \mathrm{C}$, já a terceira estratificação compreendeu a região nordeste do campus, integrando a prefeitura, o teatro universitário o IB (Instituto de Biociências) e a 
região do Centro de Humanidades com temperaturas variando de $31,4^{\circ} \mathrm{C}$ a $32,2^{\circ} \mathrm{C}$. Esta estratificação pode estar relacionada aos ventos de sudoeste que ocorreram durante todo o dia.

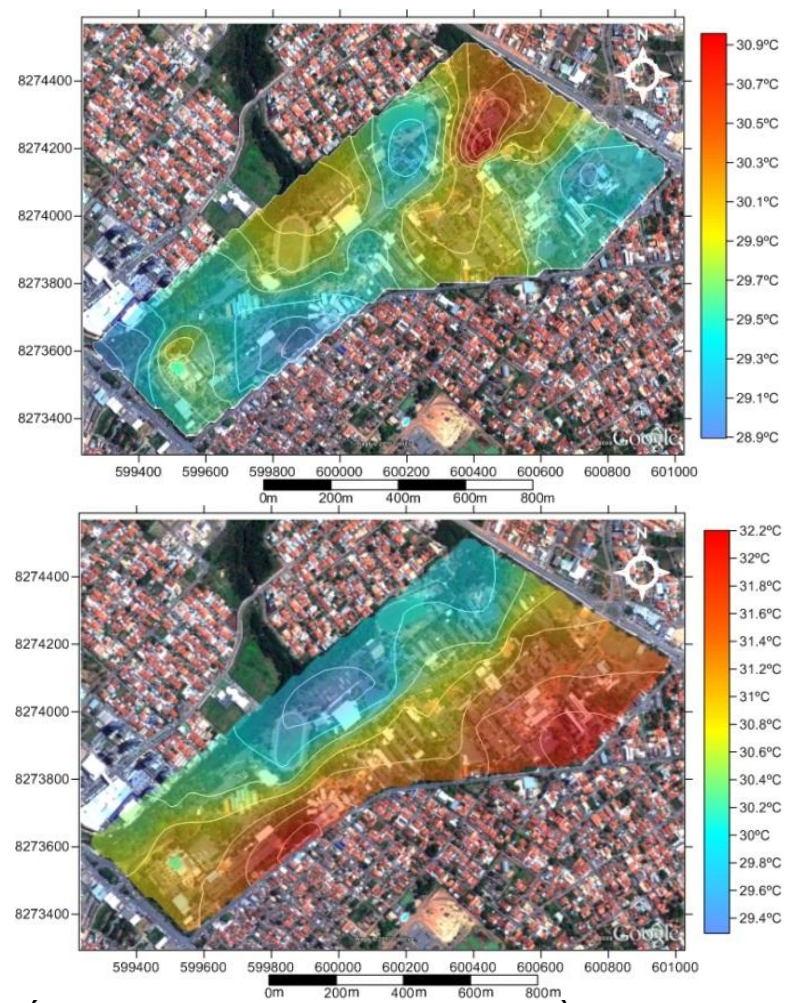

FIGURA 5 - MAPA TÉRMICO DO CAMPUS DA UFMT ÀS 20H DO DIA 26/04 (A) E MAPA TÉRMICO DO CAMPUS DA UFMT ÀS 20H DO DIA 16/09 (B).

\section{ANÁLISE ESPACIAL DA UMIDADE RELATIVA DO AR}

No mapa higrométrico das $8 \mathrm{~h}$ do dia 23 de abril (Figura $6 \mathrm{~A}$ ) pode se notar que a umidade relativa no campus teve uma amplitude de $12 \%$. Sendo que a região próxima a CAE (Coordenação de Administração Escolar), Hospital Universitário, FAMEV (Faculdade de Agronomia e Medicina Veterinária) e FENF (Faculdade de Engenharia Florestal) apresentou a menor umidade, em torno de $61 \%$, em função do aquecimento verificado no local. Já na região próxima ao PPGFA (Programa de Pós-Graduação em Física Ambiental) e ao zoológico verificou-se maiores taxas higrométricas (73\%), em decorrência da presença de lâmina d'água, e provavelmente, do escoamento de massa de ar 
úmida desde a região do casarão até o zoológico, devido a declividade do relevo.

Verifica-se na figura 6B que houve uma amplitude higrométrica de $8 \%$, na qual as áreas próximas ao zoológico (presença de vegetação e lagoa) e ao PPGFA (vegetação de copa fechada e pavimentação asfáltica) apresentaram às $8 \mathrm{~h}$ os maiores valores de umidade, na faixa de $37,5 \%$, por causa do processo de evapotranspiração. Do Centro Cultural passando pela FAMEV até - SINTUF (construções mescladas com árvores) os valores higrométricos estiveram de $31,5 \%$ a $32,5 \%$, já a área compreendida entre o parque aquático e a rua que corta a UFMT apresentou umidade na casa de $29,5 \%$, provavelmente pela presença de solo nu sem vegetação.

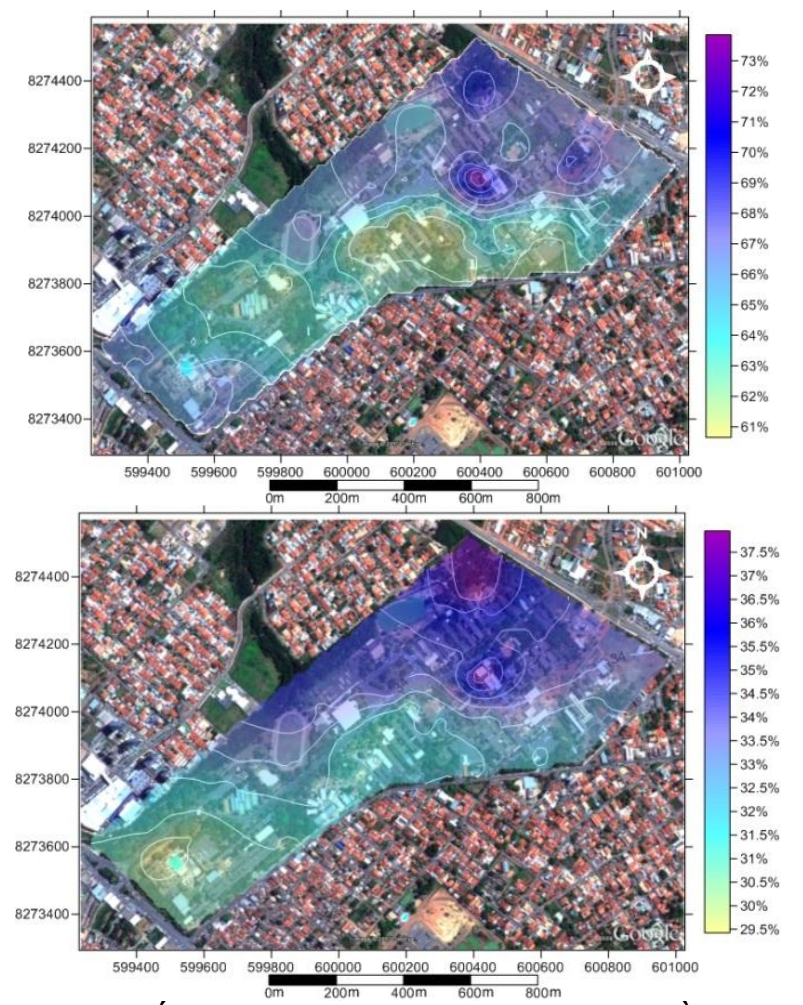

FIGURA 6 - MAPA HIGROMÉTRICO DO CAMPUS DA UFMT ÀS 8H DO DIA 23/04 (A) E MAPA HIGROMÉTRICO ÀS 08H DO DIA 13/09 (B).

Ao se comparar a figura $4 \mathrm{~A}$ com a figura $7 \mathrm{~A}$ observa-se que a umidade relativa do ar apresentou um comportamento inversamente proporcional à 
temperatura, pois essas figuras se referem ao mesmo e dia e horário de coleta. Observa-se que as regiões mais quentes apresentaram menor umidade, e que as regiões mais frias apresentaram maior umidade. Devido ao processo de evapotranspiração, a região do zoológico e de bosque (sudoeste do campus) apresentaram os maiores valores de umidade relativa do ar, entorno de $55 \%$. Enquanto que a região mais pavimentada próxima a um estacionamento apresentou umidade relativa baixa (42\%).

Por meio da figura 7B observa-se que para setembro a umidade relativa do ar esteve muito baixa em todo o campus, variando de $16,4 \%$ a $21,4 \%$, sendo que os maiores valores, em concordância com o mapa higrométrico das 8h, foram verificados na região do zoológico incluindo a lagoa e o PPGFA, confirmando a importância de lâminas d'água, principalmente no período seco. Nas proximidades da FAMEV e do Hospital Vetetinário (região de construções com árvores) apresentaram umidade relativa próxima aos $16 \%$. Já nas áreas de bosque a umidade esteve baixa, devido à falta de disponibilidade de água para a evapotranspiração, sendo que muitas árvores, principalmente as endêmicas, perderam suas folhas, fazendo com que pouca água fosse liberada para a atmosfera. 


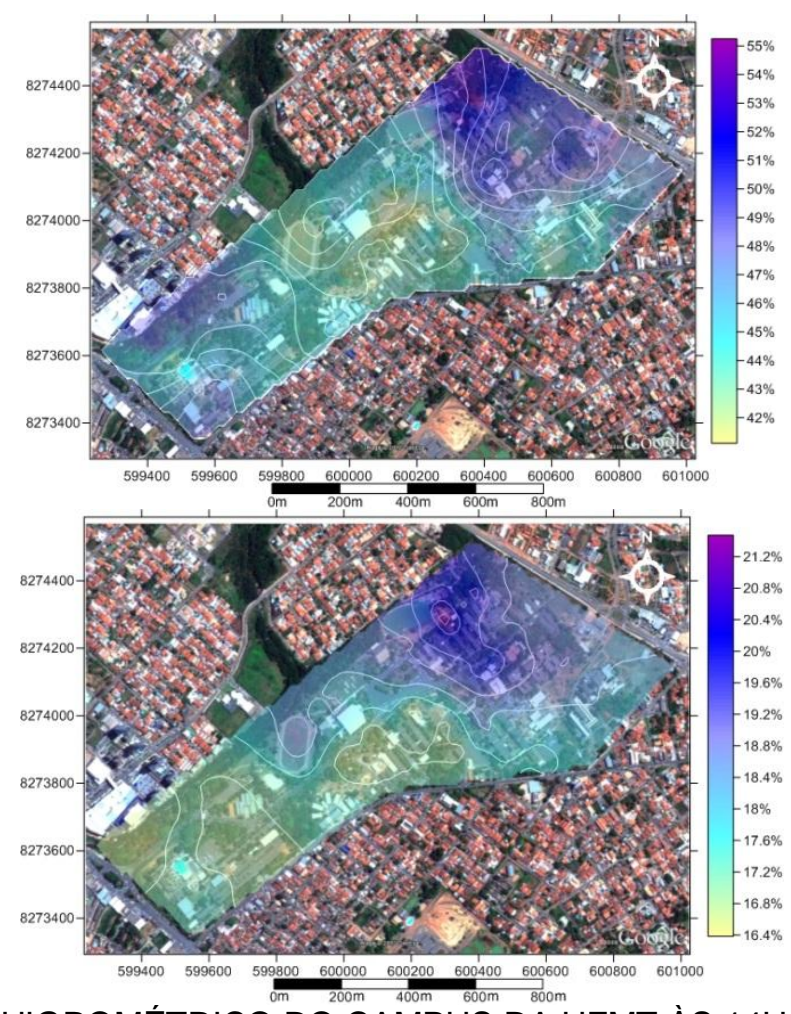

FIGURA 7 - MAPA HIGROMÉTRICO DO CAMPUS DA UFMT ÀS 14H DO DIA 21/04 (A) E MAPA HIGROMÉTRICO ÀS 14H DO DIA 12/09 (B).

Averigua-se no mapa higrométrico da figura $8 \mathrm{~A}$ uma amplitude higrométrica de 10\%, ocasionada, essencialmente, pelo antagonismo das elevadas taxas de umidade dos bosques e as baixas taxas nas áreas construídas, principalmente pelos estacionamentos próximos ao ginásio de esportes, ao SINTUF (Sindicato dos trabalhadores da UFMT) e ao ICHS. Nestes locais há pouca evaporação, visto que nessas áreas impermeabilizadas a água precipitada pela chuva não se infiltra no solo, ela escoa. Sendo que a evapotranspiração, acaba sendo mínima, devido à falta de áreas vegetadas.

$\mathrm{Na}$ figura 8B é possível verificar a presença de anomalias, que devem ter sido condicionadas em função das especificidades microclimáticas de cada local, nota-se que a área da lagoa e parque aquático apresentou umidade relativa entre $44 \%$ a $47 \%$, tendo o campo de futebol apresentado o maior valor higrométrico, umidade esta que deve ter sua origem no córrego do barbado, sendo transportada por ventos WNW (Norte-Nordeste). No PPGFA a umidade 
esteve na casa dos $40 \%$, assim como na biblioteca ocorreram os menores valores de umidade relativa do ar.

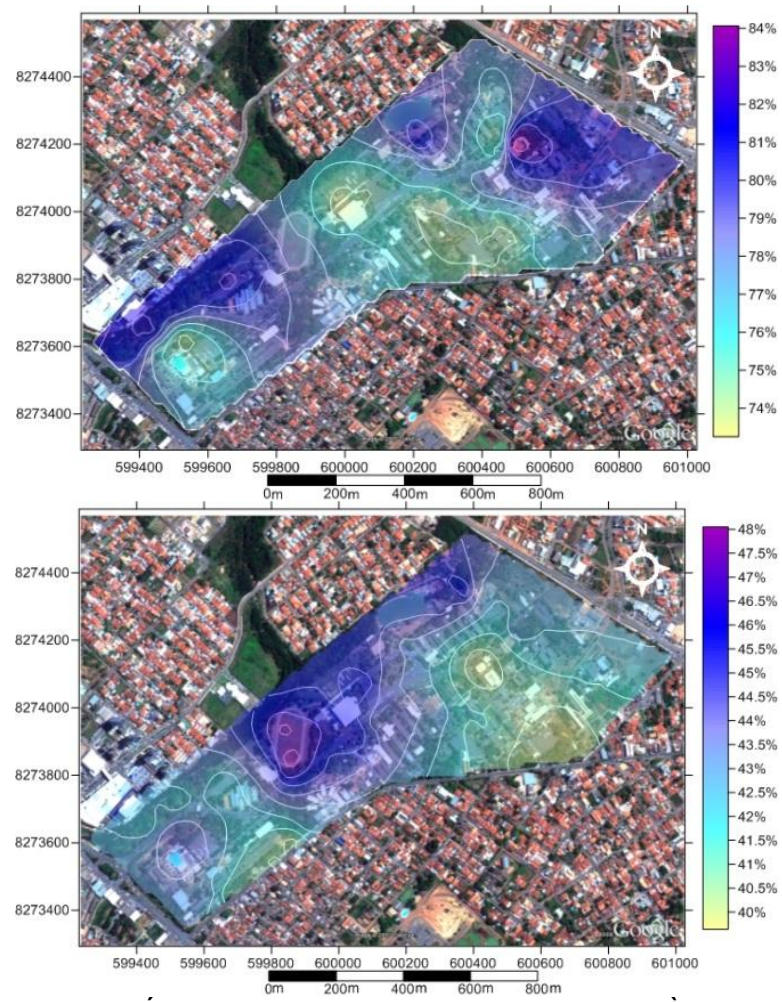

FIGURA 8 - MAPA HIGROMÉTRICO DO CAMPUS DA UFMT ÀS 20H DO DIA 27/04 (A) E MAPA HIGROMÉTRICO DO CAMPUS DA UFMT ÀS 20H DO DIA 16/09 (B).

\section{CONSIDERAÇÕES FINAIS}

O estudo microclimático realizado na Universidade Federal de Mato Grosso, Campus de Cuiabá, confirmou a evidência de que existe uma relação entre os tipos de uso e ocupação do solo e a topografia sobre a temperatura e umidade relativa do ar.

Os diferentes microclimas da Universidade são influenciados pela combinação de todos os fatores heterogêneos, pela mata, pela proximidade a corpos d'água, pela presença de superfícies gramadas, pelos pavimentos, e 
edifícios, sendo que os dados micrometeorológicos proporcionaram informação na escala local, e não somente do efeito do solo adjacente.

Em linhas gerais, os pontos com áreas verdes mostraram-se importantes, tanto para o aumento da umidade, como para a redução da temperatura do ar, principalmente no período chuvoso, pois no período seco boa parte das árvores perderam suas folhas. A região do zoológico revelou-se importante para o acréscimo de umidade no ar devido à presença de superfície com água (lagoa) em sua proximidade e da topografia, proporcionando escoamento das massas de ar.

Nos locais sem obstrução, campo de futebol, estacionamentos, verificouse temperaturas elevadas, devido à falta de interceptação da radiação solar, e também do tipo de superfície, no caso grama e pavimento asfáltico.

\section{SUGESTÕES AO PLANEJAMENTO DA UNIVERSIDADE FEDERAL DE MATO GROSSO}

Por meio da espacialização da temperatura e umidade relativa pode-se fazer as seguintes recomendações para o planejamento do campus:

1. Implantação de áreas verdes com espécies lenhosas de grande porte, em espaços abertos, principalmente nos estacionamentos e nos canteiros centrais, em função do sombreamento das árvores reduzirem as temperaturas de superfície que estão abaixo delas, e retirarem calor sensível do ar no processo de evapotranspiração, transformando-o em calor latente, minimizando a temperatura do ar e aumentando a umidade relativa.

2. Criação de superfícies de água, próxima ao campo de futebol para elevar a umidade relativa do ar naquela região, pois a umidade esteve crítica no mês de setembro, chegando a 16,4\%, valor considerado prejudicial à saúde, segundo a OMS (Organização Mundial da Saúde).

3. Mesclar as áreas gramadas com árvores, pois o solo coberto somente por grama mostrou-se capaz de reemitir rapidamente a radiação de ondas longas, aquecendo o ar. As árvores interceptariam parte da radiação solar, diminuindo a energia reemitada pelo solo. 
4. Diminuir as áreas de calçamento.

5. Substituir os pavimentos asfálticos por pavimentos de concreto, o que levaria a um menor aquecimento do ar. Pois em estudo realizado no Japão, Asaeda et al.(1996) observou que um pavimento asfáltico com reflectância solar de $10 \%$ chegou a $66^{\circ} \mathrm{C}$ e conveccionou cerca de $350 \mathrm{Wm}^{2}$, já pavimento de concreto com reflectância de $45 \%$ chegou a $49^{\circ} \mathrm{C}$ e emitiu apenas cerca de $200 \mathrm{Wm}^{2}$ para o ar.

6. Introdução de superfícies porosas em detrimentos das superfícies impermeabilizadas, para que a água da chuva escoe por entre o pavimento e seja armazenada nas camadas do solo abaixo dele, para que essa água possa evaporar resfriando o pavimento em dias ensolarados.

\section{REFERÊNCIAS}

DAVIS, S. J.; CALDEIRA, K.; MATTHEWS, H. D. Future $\mathrm{CO}_{2}$ Emissions and Climate Change from Existing Energy Infrastructure. Science, v. 329 n. 5997, p. 1330-1333, 2010.

ELIASSON, I.; UPMANIS, H. Nocturnal Airflow from Urban Parks-Implications for City Ventilation. Theoretical and Applied Climatology, v. 66, n. 1-2, p. 95107, 2000.

GARTLAND, L. Ilhas de calor: como mitigar zonas de calor em áreas urbanas. Tradução: 1. ed. São Paulo: Oficina de textos, 2010, 248p.

JANSSON, C. Urban microclimate and surface hydrometeorological processes. TRITA-LWR PHD 1027. Doctoral Thesis in Land and Water Resources Sciences. KTH Architecture and the Built Environment, Stockholm. 2006, 32p.

JAUREGUI, E. Influence of a large urban park on temperature and convective precipitation in a tropical city. Energy and Buildings, v. 15, n. 3-4, p. 457-463, 1990-1991.

KOLOKOTRONI, M.; ZHANG, Y.; WATKINS, R. The London Heat Island and building cooling design, Solar Energy, v. 81, n. 1, p. 102-110, 2007.

KREUZWIESER, J.; GESSLER, A. Global climate change and tree nutrition: influence of water availability. Tree physiology, v. 30, n. 9, p. 1221-1234, 2010.

OFFERLE, B.; JONSSON, P.; ELIASSON, I.; GRIMMOND, C. S. B. Urban Modification of the Surface Energy Balance in the West African Sahel: Ouagadougou, Burkina Faso. Journal of Climate, v. 18, n. 19, p. 3983-3995, 2005. 
POTCHTER, O.; COHEN, P.; YAAKOV, Y.; BITAN, A. The climatic behavior of various types of urban parks in a coastal Mediterranean city during the summer - the case of Tel Aviv, Israel. In: Fifth International Conference on Urban Climate, 2003, Lodz, Polônia.

POTCHTER, O.; COHEN, P.; BITAN, A. Climatic behavior of various urban parks during hot and humid summer in the Mediterranean city of Tel Aviv, Israel. International Journal of Climatology, v. 26, p. 1695-1711, 2006.

PRADO, R. T. A.; FERREIRA, F. L. Measurement of albedo and analysis of its influence the surface temperature of building roof materials, Energy and Buildings, v. 37, n. 4, p. 295-300, 2005.

RIBEIRO, A. G. As Escalas do Clima. Boletim de Geografia Teorética, v. 23, n. 45-46, p. 288-294, 1993.

SHASHUA-BAR, L.; POTCHTER, O.; BITAN, A.; BOLTANSKY D.; YAAKOV, Y. Microclimate modelling of street tree species effects within the varied urban morphology in the Mediterranean city of Tel Aviv, Israel. International Journal of Climatology, v. 30, n. 1, p. 44-57, 2010.

STREILING, S.; MATZARAKIS, A. Influence of Single and Small Clusters of Trees on the Bioclimate of a City: A Case Study. Journal of Arboriculture, v. 29, n. 6, p. 309-316, 2003.

VÖRÖSMARTY, C. J.; GREEN, P.; SALISBURY, J.; LAMMERS, R. B. Global Water Resources: Vulnerability from Climate Change and Population Growth. Science, v. 289, n. 5477, p. 284-288, 2000.

WONG, N. H.; JUSUF, S. K.; WIN, A. A. L.; THU, H. K.; NEGARA, T. S.; $\mathrm{XUCHAO}, \mathrm{W}$. Environmental study of the impact of greenery in an institutional campus in the tropics. Building and Environment, v. 42,p.2949-2970,2007. 